\title{
Da Educação Superior: Um estudo sobre a Relação Professor-Aluno à partir da Perspectiva Psicanalítica
}

\author{
Débora dos Santos Silva ${ }^{l}$;Raul Max Lucas da Costa ${ }^{2}$
}

Resumo: O artigo pretende abordar as vicissitudes do processo de ensino-aprendizagem na educação superior, evidenciando os principais sujeitos envolvidos em tal processo, a saber: professores e alunos. Sendo assim, recorreu-se à abordagem qualitativa de caráter bibliográfico. Utilizou-se como base ou unidade de análise a perspectiva psicanalítica que trabalha categorias como: afetividade, transferência, desejo de saber e discurso como laço social. Trabalhou-se também com teóricos que tratam especificamente da educação superior. Neste sentido, faz-se uma interface entre educação e psicanálise no intuito de propiciar uma maior compreensão da relação professor-aluno enquanto principal instrumento para que ocorra ou não aprendizagem e para que o desejo de saber do discente possa ser desenvolvido e constituir-se em verdadeiro campo para a construção de conhecimentos científicos.

Palavras-chave: Professor. Aluno. Transferência. Desejo de Saber. Discurso.

\section{Higher Education: A Study on Teacher-Student Relationship by Psychoanalytic Perspective}

\begin{abstract}
This article aims to address the events of the teaching-learning process in higher education, highlighting the main subjects involved in this process, namely: teachers and students. Therefore, appealed to the qualitative approach of bibliographical character. It was used as a base or unit of analysis psychoanalytic perspective working categories such as affection, transfer, desire to know and speech as a social bond. It also worked with theorists who deal specifically with higher education. In this sense, it is an interface between education and psychoanalysis in order to encourage a greater understanding of teacher-student relationship as the main instrument to occur or not learning and the desire to know the student can be developed and form themselves into true field for the construction of scientific knowledge.
\end{abstract}

Keywords: Teacher. Student. Transfer. Desire to Know. Speech.

\section{Introdução}

No ambiente educacional busca-se proporcionar aos alunos o acesso aos bens culturais e científicos conquistados e estabelecidos ao longo da história da humanidade. A metodologia, a didática de ensino e os recursos tecnológicos são instrumentos que o professor utiliza para tornar possível a transmissão do conhecimento acumulado pela sociedade. Neste sentido, muitos estudiosos do desenvolvimento e da aprendizagem procuraram e procuram favorecer meios efetivos para que o docente possa conquistar tal intuito.

\footnotetext{
${ }^{1}$ Psicóloga, graduada pela Faculdade Leão Sampaio - FALS. Especialista em Educação Inclusiva com Ênfase em Atendimento Educacional Especializado e pós-graduanda (lato sensu) em Prática Docente do Ensino Superior pelas Faculdades Integradas de Patos - FIP. Membro titular do Comitê de Ética em Pesquisa da Faculdade de Juazeiro do Norte - FJN. E-mail: deborassilva25@ gmail.com;

${ }^{2}$ Graduado em História pela Universidade Estadual do Ceará - UECE. Graduado em Psicologia pela Universidade de Fortaleza - UNIFOR. Mestre em História Social pela Universidade Federal do Ceará - UFC. Doutorando em Psicologia pela UNIFOR. É professor no curso de Psicologia da Faculdade Leão Sampaio - FALS e psicólogo do Núcleo de Apoio à Saúde da Família - NASF da Secretaria de Saúde de Juazeiro do Norte. Membro da Invenção Freudiana - Transmissão da Psicanálise, Fortaleza-CE. E-mail: raulmaxpsi @ yahoo.com.br.
} 
Entretanto, a ênfase na transmissão de conceitos e o grande aparato tecnológico que se possui hoje, terminam por favorecer mais a busca por memorização e acúmulo de informação do que o desenvolvimento humano e cidadão, visto que os estudantes desde o ensino básico estão sendo preparados para o vestibular e quando já estão no ensino superior começam a ser preparados para almejar graus mais avançados na hierarquia acadêmica. Inseridos nesta lógica, aqueles que não conseguem acompanhar tal sistema de ensino acabam por ser taxados de desinteressados, não inteligentes, indisciplinados. Percebe-se um foco maior nos aspectos cognitivos do que nos aspectos afetivos subjacentes ao ato de ensinar e ao desejo de aprender e de construir, por conseguinte, ciência.

Com efeito, a falta de interesse do aluno em determinada disciplina ou um grande interesse pode, e muitas vezes, advém da relação negativa ou positiva estabelecida com o professor. Sendo assim, é preciso que os docentes de nível superior compreendam que no processo de ensinoaprendizagem existem muitas questões envolvidas para além daquilo que o professor pensa transmitir e o aluno supõe entender.

Estes aspectos irão ser tratados neste trabalho a partir de conceitos como afetividade, transferência, desejo de saber e discurso como laço social, próprios de uma perspectiva psicanalítica freudo-lacaniana.

\section{Sobre a Educação Superior e a Concepção Psicanalítica}

Antes de falar especificamente da vertente psicanalítica e como ela pode contribuir para o entendimento dos processos inerentes à transmissão e aquisição de conhecimento na relação professoraluno, pretende-se descrever como foi acontecendo desde a época do Brasil colonial a procura, acesso e modo de funcionamento da educação superior.

De acordo com Masetto (1998), na época do Brasil colônia não haviam cursos superiores. Os cursos de terceiro grau tiveram início apenas a partir do ano 1808, momento em que a Coroa Portuguesa ${ }^{1}$ estabeleceu-se em terras brasileiras. Percebeu-se aí a necessidade de inserir cursos superiores a fim de garantir estudos aprofundados e de qualidade aos novos habitantes.

Estes cursos, segundo o autor, se voltavam quase que exclusivamente à formação de profissionais para atender as demandas do mercado de trabalho que, aos poucos, começava a exigir mão de obra qualificada. Sendo, portanto, constituídos de currículos, programas não flexíveis e com foco na especialidade a ser desenvolvida. Logo, a educação e as metodologias de ensino eram compostas por disciplinas ministradas de forma expositiva pelo docente, detentor do saber, ao aluno

\footnotetext{
${ }^{1}$ Na pessoa do Rei de Portugal e sua comitiva.

39 Id en line Revista de Psicologia. Ano 9, No. 27. Julho/2015 - ISSN 1981-1179. Edição eletrônica em http://idonline.emnuvens.com.br/id
} 
que era, por sua vez, considerado como desprovido de saber. Este saber ele alcançaria com o curso escolhido e a avaliação é que diria se o mesmo estaria apto ou não ao exercício profissional.

Neste sentido, a própria terminologia da palavra aluno, que vem do latim (alumnus), e significa $^{2}$ criança de peito, lactente ou aquele que é alimentado e o significado da palavra professor, também de origem latina, e que significa ${ }^{3}$ professar/declarar publicamente, acaba por trazer a ideia de que o professor é aquele que detém o saber e o aluno é o que irá em direção deste saber: saindo das trevas da ignorância no intuito de alcançar a luz.

Além disso, por um longo período acreditou-se que o profissional habilitado em determinada área do conhecimento saberia também repassar tal conhecimento com didática e metodologia.

Só recentemente os professores universitários começaram a se conscientizar de que a docência, como a pesquisa e o exercício de qualquer profissão, exige capacitação própria e específica. O exercício docente no ensino superior exige competências específicas, que não se restringem a ter um diploma de bacharel, ou mesmo de mestre ou doutor, ou, ainda, apenas o exercício de uma profissão. Exige isso tudo, além de outras competências próprias [...] (MASETTO, 1998, p. 11).

Deste modo, no passado o objetivo do aluno nas salas de aula de ensino superior era o de transformar-se num profissional (com especificidades bem constituídas) e o professor era o centro do processo, já que era considerado o dono do saber e sua metodologia não era questionada quando ocorria fracasso escolar de grande quantidade dos discentes. Hoje, em contrapartida, fala-se que o centro do processo é o aluno. Sendo que o professor deve ser um facilitador e fomentador do interesse dos discentes ao favorecer o aprendizado com práticas pedagógicas adequadas (MASETTO, 1998).

Contudo, deve-se entender que, segundo Gaetta e Masetto (2013), no início da vida acadêmica os estudantes têm uma maior necessidade de um ensino focado numa perspectiva mais conteudista e com o passar do tempo o aluno vai ganhando mais independência e experiência intelectual, nesse momento, o foco na aprendizagem deve ser preponderante pela compreensão por parte do professor de que o aluno tornou-se o principal personagem no processo de aquisição de conhecimento. Estes dois processos, de acordo com os autores, estão relacionados aos métodos da pedagogia e da andragogia, respectivamente.

Neste sentido, a docência do ensino superior implica mais do que o domínio de conhecimentos a serem transmitidos à maneira de educação bancária, onde, no dizer de Paulo Freire (1987), a tarefa daquele que educa é a de preencher de conteúdos o educando. Conteúdos estes, muitas vezes, desprovidos de sentido pelo fato de estarem fragmentados e não relacionados ao contexto da vida real.

O aluno, nesta perspectiva criticada por Freire, é como uma espécie de recipiente que recebe o conhecimento de forma passiva. No entanto, esta concepção de ensino não mais se justifica numa

\footnotetext{
${ }^{2}$ Segundo o site Filosofando.

${ }^{3}$ Segundo o site Assim Mesmo. 
sociedade globalizada onde o conhecimento é produzido e transmitido de forma rápida e constante, através de mídias como a internet.

Muitos temas em matéria de educação têm sido avaliados, questionados e modificados para fazer frente à realidade social tecnologicamente informatizada. A educação superior não pode ficar omissa a estas mudanças. Os docentes precisam estar atentos a tais transformações e angariar capacidades para responder a esta situação. É assim que, segundo Masetto (1998), no atual panorama, o processo de aprendizagem do aluno deve ser de fato o objetivo central dos cursos superiores.

Os profissionais docentes devem assumir habilidades e competências totais, não mais em uma área específica. É preciso que compreendam os aspectos cognitivos, emocionais e afetivos que o processo de ensino-aprendizagem comporta. Estas habilidades e competências são desenvolvidas por meio de reciclagem ininterrupta, através de pesquisas que venham a beneficiar a sociedade e de reflexão em torno da prática pedagógica. Temas referentes à inclusão educacional, bullying, novas formas de família, preconceito racial, sexual e de gênero também devem entrar na pauta das reflexões dos docentes do ensino superior.

Neste sentido, o professor precisa ser também um profissional inclusivo. Porém, para tal, o docente deve, segundo Baptista (2006), apostar em dois planos: o do autoconhecimento (pois tem de lidar com inúmeras subjetividades e realidades e responder adequadamente às demandas dos estudantes), e o da busca por referenciais de atuação (na medida em que é necessário recorrer a teóricos e propostas já em uso na história da educação).

Enfim, as universidades e as faculdades possuem regimentos e estatutos próprios, diferentes das concernentes ao ensino básico e médio. Possuindo, entre suas características, a autonomia e a liberdade de pesquisa e produção de conhecimento, desde que pautados na Ética e nas normatizações estatais. Estas características, de certa forma, já existem desde a época em que se inseriu o ensino superior no país. O que difere é o modo de fazer pesquisa, de transmitir conhecimento e de incentivar a extensão universitária, além, é claro, da concepção de homem (e de mulher) que vai se alterando ao longo do tempo.

\section{O Ensino Superior na Atualidade}

Portanto, na didática tradicional o foco era no ensino, o centro do processo era o professor, o aluno era visto como um acumulador e reprodutor de informações e os instrumentos de avaliação eram, muitas vezes, estruturados de forma que dificultasse a livre expressão do discente; no atual contexto, em contrapartida, existe a ênfase no processo do ensinar e do aprender, o centro deste processo é o aluno, sendo o papel do professor o de incentivador ou estimulador do mesmo.

Nesta perspectiva, Roldão (2007) disserta sobre a natureza e a função do professor do ensino superior. Das ideias que traz em seu texto destacam-se as seguintes:

41 Id en line Revista de Psicologia. Ano 9, No. 27. Julho/2015 - ISSN 1981-1179. Edição eletrônica em http://idonline.emnuvens.com.br/id 
- Na atualidade a função de ensinar implica fazer aprender.

- É necessário definir as especificidades da profissão docente. Pois, muitas das dificuldades na delimitação desta função devem-se ao fato de a ação de ensinar vir antes da formação para ensinar.

- O educador deve estar ciente sobre a abordagem ou visão de homem/mundo que possui. Com efeito, a autora cita duas perspectivas que muitas vezes entravam o processo de ensinoaprendizagem, a saber: a perspectiva tecnocrática (orientada pelos conceitos do behaviorismo radical, entre outros) e a perspectiva terapêutica relacional (orientada pela matriz personalista ou de não diretividade: exemplo disso [a nosso ver] é o rogerianismo ${ }^{4}$ na educação). Ambas, "[...] empurram a função de ensinar ora para a indefinição ora para a tecnicização [...]" (ROLDÃO, 2007, p. 97).

Ou seja, o profissional professor possui especifidade própria a sua ação educativa e não deve, pura e simplesmente, se embasar em pensadores ou teóricos sem adequar seus conceitos à natureza desta ação. Ademais, é preciso ter em mente o posicionamento ético frente à função docente, uma ética voltada para a transmissão e construção de conhecimentos, mas também ciente de que conhecimento é poder, e precisa estar direcionado a todos, independentemente de questões raciais, religiosas e culturais. Além disso, esta ética deve atuar, adverti-nos Freire (2002[1996]), até no modo em que o professor trabalha uma obra, na forma como cita determinados autores, nas próprias simpatias ou antipatias que tem por determinados assuntos e teóricos e como deixa transparecer estes sentimentos.

O docente do ensino superior deve estar atento ao seu comportamento, o tipo de mensagem que passa e o tipo de profissional que pretende ajudar a formar, já que o aluno tem uma forte tendência a se identificar ${ }^{5}$ com o professor e colocá-lo como modelo de conduta. Neste sentido, Freud, no texto Algumas reflexões sobre a psicologia do Escolar (1996 [1914]), faz menção à relação que tinha com seus mestres, relação esta muitas vezes perpassada por sentimentos ambivalentes que não possuíam base na realidade objetiva. Este escrito demonstra a importância da figura do professor (com seu temperamento e caráter) interferindo ou estimulando o desejo de saber dos discentes. Nas palavras de Freud:

[...] é difícil dizer se o que exerceu mais influência sobre nós e teve importância maior foi a nossa preocupação pelas ciências que nos eram ensinadas, ou pela personalidade de nossos mestres [...] e, para muitos, os caminhos das ciências passavam apenas através de nossos professores [...].

[...] Nós os cortejávamos ou lhes virávamos as costas; imaginávamos neles simpatias e antipatias que provavelmente não existiam; estudávamos seus caráteres e sobre estes formávamos ou deformávamos os nossos [...] No fundo, sentíamos grande afeição por eles, se nos davam algum fundamento para ela, embora não possa dizer

\footnotetext{
${ }^{4}$ Baseados nos ensinamentos do Psicólogo estadunidense Carl Rogers.

${ }^{5}$ Identificação: refere-se ao processo em que um sujeito se institui e se modifica, em determinados momentos de seu desenvolvimento, a partir da assimilação ou apropriação de características das pessoas que o rodeiam (ROUDINESCO; PLON, 1998). 
quantos se davam conta disso [...] Estávamos, desde o princípio, igualmente inclinados a amá-los e a odiá-los, a criticá-los e a respeitá-los. (FREUD, 1996, p.248).

\section{A Educação numa Perspectiva Psicanalítica}

Em Análise terminável e interminável (1996[1937]), Freud dirá existir três profissões impossíveis, a saber: psicanalisar, governar e educar. Esta impossibilidade pode remeter ao fato de que a função do psicanalista, do político e do professor se relacionem com o contraditório e ao mesmo tempo sedutor ofício (na escuta e na emissão) da palavra. É no dizer que se pode demonstrar uma posição diante do mundo e dos outros seres, e, ainda, provocar o ouvinte/interlocutor a dar seu próprio posicionamento diante das situações.

Se levarmos estas ideias para outro campo: o da música ${ }^{6}$, poderemos pensar no fato curioso de que sempre ${ }^{7}$ dentro de um conjunto musical (uma banda) por mais que o intelectual, compositor e idealizador do mesmo seja o tecladista, baterista ou guitarrista a popularidade e o estrelato recaem sobre o vocalista, justamente pelo fato deste exercer com a voz certo papel transferencial para com os fãs.

Porém, a diferença entre o uso da fala no músico/cantor e nas três profissões (educar, psicanalisar e governar) é de que, nas últimas, o impossível remete a uma aposta, incerta, em um resultado dado por um sujeito, já a primeira - enquanto arte - acena para a ideia da apreciação e contemplação estética e do fato de o artista "[...] dar forma a seus devaneios de modo [...] que [...] perdem aquilo que [...] é [...] pessoal e que afasta as demais pessoas, possibilitando que [...] compartilhem [...] [d]esses devaneios [...]" (FREUD, 1996 [1916-1917], p. 378).

Voltando para a temática da educação, é necessário pensá-la e debatê-la não só a partir dos conceitos referentes à inteligência ou cognição, mas de como, no processo de conhecer, o sujeito vai se interessando por determinadas áreas e temas em detrimento de outros e como a afetividade está diretamente relacionada a estes processos. Neste sentido, Lajonquière no livro De Piaget a Freud (1998), propõe discutir as vicissitudes por qual passa um sujeito na aquisição das aprendizagens tratando de demonstrar que os erros (às vezes mais que os acertos) exercem uma função importante para as equilibrações e sistematizações do conhecimento. Podendo ser até "[...] produtos sobredeterminados da inteligência e do desejo inconsciente" (LAJONQUIÈRE, 1998, p. 148, grifo do autor).

Compreender que a afetividade está em jogo no percurso de adquirir conhecimento é importante tanto para entender os erros recorrentes neste processo quanto para favorecer o desabrochar

\footnotetext{
${ }^{6}$ Para exemplificar o que estamos dizendo.

${ }^{7}$ Deve existir uma exceção, porém, em regra é assim.

43 Id en line Revista de Psicologia. Ano 9, No. 27. Julho/2015 - ISSN 1981-1179. Edição eletrônica em http://idonline.emnuvens.com.br/id
} 
das potencialidades dos educandos. É assim que, ainda segundo o autor, o próprio Piaget não olvidou tal importância, se expressando nos termos abaixo:

[...] a afetividade é fundamental como motor da ação. Se não nos interessamos por alguma coisa, nada fazemos, certamente [...] [porém] eu me interesso pelo que é geral no desenvolvimento da inteligência e do conhecimento, enquanto que a psicanálise é, por essência, uma análise das situações individuais, dos problemas individuais. (PIAGET, apud LAJONQUIÈRE, 1998, pp. 120-21).

É assim que a psicanálise pode dizer algo sobre a afetividade, manifesta nos desejos conscientes e inconscientes, nas facilidades e angústias no processo de adquirir conhecimento e ainda ofertando à Educação, encarnada na figura do professor, uma ferramenta para se atingir o objetivo do ensino: que é a aprendizagem. E, mais do que isto, o despertar constante do aluno para a interminável busca pelo saber.

Sobre isto, Freud, em Explicações, aplicações e orientações (1996[1933]), dissertará sobre o papel do professor na educação escolar das crianças e distinguirá quatro aspectos da ação docente: 1) deve reconhecer a individualidade constitucional do objeto de sua influência educacional; 2) Inferir o que está se passando na mente do aluno; 3) Oferecer a quantidade adequada de amor; 4) Manter, em contrapartida, um grau eficaz de autoridade. Acredita-se que estas noções podem, sem problema nenhum, ser deslocadas para a educação superior, na medida em que se percebe atuante neste campo, na relação professor-aluno, questões concernentes a: identificações, transferências, contratransferências e discursos que geram ditos: bem-ditos e mal-ditos.

\section{Afetividade, Transferência, Desejo de Saber e Discurso no Contexto Educacional Superior}

Segundo o Minidicionário da língua portuguesa, de Bueno (2007), a palavra afetividade significa: “[...] Qualidade do que é afetivo; afeição; carinho [...]”. Por sua vez Dalgalarrondo (2008) define do seguinte modo: “A vida afetiva é a dimensão psíquica que dá cor [...] e calor a todas as vivências humanas $[\ldots]$ compreende várias modalidades de vivências $[\ldots]$ como [...] humor, [...] emoções e [...] sentimentos" (DALGALARRONDO, 2008, p. 155, grifo do autor). Na relação professor-aluno e de ensino-aprendizagem, Almeida (1993) diz que a afetividade é um

[...] elemento inseparável e irredutível das estruturas da inteligência. [...] na transmissão e apropriação do conhecimento, que ocorre numa relação sujeito a sujeito, intervêm processos conscientes e inconscientes dos pares em relação. Não há ato de ensinar-aprender sem a mediação concreta de sujeitos humanos, não havendo, portanto, relação ensino-aprendizagem sem que haja atuação indissociável entre inteligência, afetividade e desejo (ALMEIDA, 1993, p. 31, grifo da autora). 
A autora menciona, assim, a importância de se perceber atuante a afetividade enquanto elemento inseparável da dimensão intelectiva, onde o professor precisa também estar ciente de como é afetado pelas demandas do educando.

Ademais, para melhor compreender a importância da relação professor-aluno na transmissão e desejo de saber é interessante mencionar o conceito de discurso na psicanálise lacaniana.

Ao longo de seus seminários, Lacan irá destrinchar alguns conceitos e defini-los através de matemas $^{8}$. Neste sentido, ele tratará de quatro discursos responsáveis pela possibilidade da comunicação humana e manutenção dos laços sociais e que remetem ao fato de se estar sempre situado em determinada posição quando se fala. Sendo que, a posição de onde se fala é mais importante do que aquilo que se fala (FORBES, s/d.). Portanto, Lacan menciona quatro discursos: discurso do mestre, discurso do analista, discurso da histérica e discurso universitário ${ }^{9}$. Respectivamente, o discurso do reconhecimento, o discurso da interpretação, o discurso da sedução e o discurso do escravo submetido ao produto do saber (BATTAGLIA, 2005). Para compor as equações algébricas de cada discurso, Lacan destaca os seguintes elementos: S1 (sujeito/significante unário), S2 (saber/significante binário), $\$$ (sujeito dividido), $a$ (objeto $a^{10}$ ). (FORBES, s/d.).

A questão central destes discursos está na posição, segundo os lacanianos, que o saber ocupa para o sujeito. Sendo, justamente por isso, que a transferência é situada, no setting psicanalítico lacaniano, quando aparece a suposição de sujeito suposto saber ${ }^{11}$ do analisando para com o analista. Enquanto na perspectiva psicanalítica freudiana, a existência da transferência se manifestaria através do investimento de afetos e sentimentos do analisando para com o analista. (SILVESTRE, 1994).

Enfim, o discurso da histérica e o discurso do mestre não serão descritos neste trabalho. O foco será dado ao discurso universitário e ao discurso do analista ${ }^{12}$ na tentativa de descrever as relações que são e que deveriam ser travadas na educação superior por professores e alunos, a partir do deslocando de um conceito tecido na clínica lacaniana.

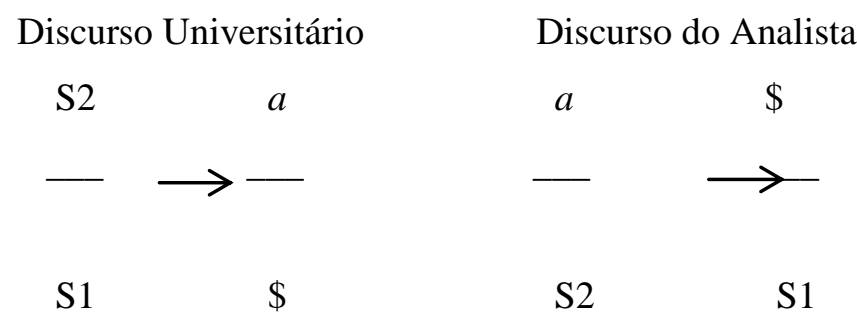

\footnotetext{
${ }^{8}$ Termo criado por Lacan para designar formas matemáticas que descrevem os conceitos psicanalíticos.

${ }^{9}$ Mais tarde em seu ensino, Lacan falará de um quinto discurso: o discurso do Capitalista.

${ }^{10}$ Objeto causa de desejo.

${ }^{11}$ Suposição de deciframento sobre a verdade dos sintomas. Esta é a suposição que o analisando, num primeiro momento da transferência, acredita estar nas mãos do analista.

${ }^{12}$ Não serão descritos aqui os quatro discursos em pormenores. Para aqueles que se interessaram sobre tais conceitos, remete-se à leitura da conferência proferida pelo psicanalista lacaniano Jorge Forbes (Os eixos da subversão analítica: os quatro discursos), utilizada no presente trabalho.

45 Id en line Revista de Psicologia. Ano 9, No. 27. Julho/2015 - ISSN 1981-1179. Edição eletrônica em http://idonline.emnuvens.com.br/id
} 
Sendo que do lado esquerdo (de cada equação) e acima se tem o agente, do lado esquerdo e abaixo se tem a verdade, do lado direito e acima se tem o outro e do lado direito e abaixo se tem a produção (MELLO, 2010). Em outros termos, existe um agente que ao sustentar uma verdade, a direciona sobre o outro a fim de conseguir uma produção.

É necessário entender o seguinte: no discurso universitário o saber coloca-se no lugar do agente e é dirigido ao objeto $a$, na busca de nomear o inominável e de colocar o sujeito como objeto de um saber que acaba por oprimi-lo e escravizá-lo, na medida em que não sabe o que fazer ou como dar sentido no campo do real ao vasto cabedal de conhecimentos adquiridos pela via da cognição e da inteligência. "[...] O resultado produzido é um sujeito dividido, de plena posse de saberes, informações e teorias, mas completamente incapaz de servir-se delas para se orientar na vida, bem como orientar a dos demais [...]" (MELLO, 2010, p. 170).

Este, portanto, é um discurso que tem sua base no Mestre (FORBES, s/d.), o transmissor de uma verdade, a verdade da ciência, amparado por outros mestres do saber, para o aluno que se apropria desta verdade que, por sua vez, não diz nada referente à sua divisão subjetiva e não consegue fazer frente ao real da angústia que inúmeras vezes acomete os discentes a partir das discussões feitas e das próprias constatações, entendimentos e confusões que o uso da linguagem pode gerar durante as aulas. Angústia esta que, segundo Lacan (2005), é o afeto que não engana, posto ser sentido no corpo e ser o signo do desejo e ao mesmo tempo ser a constatação da falta constitutiva e nunca, por isso mesmo, preenchível, na presença do objeto a.

No discurso analítico, por sua vez, tem-se o objeto causa de desejo como agente que se endereça ao sujeito dividido. O objeto $a$ aqui é o analista que ocupa um lugar de semblante que parece causar o desejo e ao mesmo tempo promove a quebra do automatismo que impede a manifestação do sujeito desejante no analisante. Ou seja,

[...] o saber que o analista porta diz respeito ao saber do inconsciente, da cadeia de significantes, que jamais oferece um sentido último [...] Portanto, o discurso do analista, antes que oferecer um saber positivo e objetivável sobre o inconsciente, encerra, como verdade, a inconsistência simbólica da bateria significante [...] (MELLO, 2010, p. 173).

Percebe-se aí uma posição do agente para com o outro não de dominação, certeza, verdade absoluta ou de mestria, mas de possibilidade para que a vontade de saber sobre si mesmo se manifeste, para que um sujeito possa advir enquanto detentor de seus próprios significantes, de seus próprios sentidos e verdades frente a si mesmo e ao mundo. Esta, segundo defende-se neste estudo, deve ser a postura do docente do ensino superior - que compreende a necessidade de um direcionamento e um estímulo (princípio da pedagogia), mas que aposta e favorece o despertar do desejo do estudante para buscar suas próprias referências e pesquisas no âmbito acadêmico (princípio da andragogia).

Não se está defendendo que todo professor deve ser psicanalista, mas que deveria, pelo menos, conhecer as ideias psicanalíticas para melhor "[...] trabalhar [-se, no que diz respeito à sua 
transferência $[$ [...] em relação à educação [...]" e para até perceber e "[...] conhecer as fantasias com as quais [...] se veste e é vestido" (BACHA, 2006, p. 65) pelos educandos. O próprio Freud (1996[1933]) menciona o fato de que seria muito interessante a análise de professores e educadores enquanto método profilático em escolas (e, porque não dizer, nas universidades e faculdades).

O professor, pela própria posição em que ocupa no discurso universitário pode e deve atentar para a dimensão de encanto e sedução que provoca nos estudantes. E assim,

[...] No lugar da hipervalorização dos métodos de ensino e de aprendizagem, das técnicas para motivar os alunos e do arsenal tecnológico usado para diminuí-lo [...] [não obstante] o professor é a figura fundamental da educação e, por isso mesmo, sua formação deveria merecer uma atenção especial. Incluindo a sua formação psicológica, que há muito vem deixando a desejar e para a qual a psicanálise tem uma enorme e subutilizada contribuição. (BACHA, 2006, p 64).

Nesse prisma, nos artigos sobre técnica, especificamente nos textos $A$ dinâmica $d a$ transferência ${ }^{13}$ (1996[1912]) e Observações sobre o amor transferencial (novas recomendações sobre a técnica da psicanálise III) (1996/1915[1914]), Freud vai se debruçar numa questão bastante importante em psicanálise: a manifestação da transferência, tanto em seu aspecto negativo quanto positivo no tratamento psicanalítico, e dirá que este fenômeno (transferencial) não acontece apenas nas quatro paredes do consultório psicanalítico, mas em diversas situações.

O contexto educacional é um deles e a relação professor-aluno pode despertar sentimentos não só transferenciais como também contratransferenciais ${ }^{14}$. Neste sentido, pode ser bastante intrincada a teia das relações entre professores e alunos na educação superior quando não há um preparo por parte do docente em manter uma relação de amor sublimada ${ }^{15}$ com seus alunos ou de controlar os ódios e ressentimentos que possam surgir durante o semestre.

Portanto, a transferência (e a contratransferência) deve ser identificada, utilizada e ao mesmo tempo mantida em suspensão, em abstinência. Sendo que essa transferência que ocorre entre professor e aluno pode manifestar-se, segundo Almeida (1993), do lado do primeiro em desejo de poder e do lado do segundo em desejo de saber. Esta seria uma tendência que se revela neste tipo de situação, entretanto, segundo a autora, o docente precisa renunciar a este desejo de poder (ou em outras palavras, de aparecer/dar show) para que o discente possa manifestar o desejo de saber. Entretanto,

O desejo de poder, ao qual ele [o professor] tem de renunciar, para sustentar o desejo de saber do aluno, não o esvazia de seu Desejo, cujos deslocamentos e deslizamentos na cadeia de significantes constituem, dialeticamente, a essência propulsora da vida humana, permanentemente confrontada com a falta e, por essa razão mesma, eternamente desejante. (ALMEIDA, 1993, p. 43).

\footnotetext{
${ }^{13}$ Transferência: designa o processo intrínseco ao tratamento psicanalítico, onde os desejos inconscientes do sujeito referentes aos objetos externos - do passado ou presentes - começam a ser direcionados e revividos, na relação psicanalítica com o analista (ROUDINESCO; PLON, 1998).

${ }^{14}$ Contratransferência: manifestações do inconsciente do terapeuta relacionadas às manifestações transferenciais do paciente. (IDEM).

${ }^{15}$ Sublimação: atividade humana relacionada à criação artística e/ou intelectual que não possui relação direta com a sexualidade, porém retira sua energia da pulsão sexual ao investir objetos valorados socialmente. (IDEM).
} 
Daí o professor necessitar permanentemente de autoanalisar-se e de questionar o desejo, a função, a formação e a utilização da docência para não só atingir os fins da educação (que é o aprendizado), mas proporcionar também o percebimento e entendimento das pulsões ${ }^{16}$, próprias à condição humana, que os sujeitos na relação em sala de aula trazem consigo, no intuito de empregar tal entendimento para favorecer ao aluno um caminho de verdadeiro interesse científico, pautado em seus próprios questionamentos e buscas.

O professor precisa, assim, estar ciente de sua posição de autoridade e poder - posição esta que ocasionalmente gera admiração ou raiva por parte dos discentes - e manter uma conduta ética, técnica e até estética condizente com os princípios que norteiam uma relação de desigualdade hierárquica.

\section{Metodologia}

Para obter o objetivo almejado, qual seja: abordar a relação professor-aluno na educação superior a partir de uma perspectiva psicanalítica, recorreu-se à abordagem qualitativa de caráter bibliográfico. A modalidade de pesquisa bibliográfica permite o estudo de elementos dispersos ao longo do tempo. E, neste sentido, para entender os fatos ocorridos no passado nortear-se em fenômenos já descritos é uma maneira efetiva de consegui-lo (GIL, 1999). Assim, pretendeu-se desenvolver um estudo acerca da relação professor-aluno e sua importância no processo de ensinoaprendizagem na educação superior.

Utilizou-se como parâmetro ou unidade de análise a perspectiva psicanalítica que trabalha categorias como: afetividade, transferência, desejo de saber e discurso como laço social, no intuito de melhor vislumbrar as vicissitudes do processo de ensino-aprendizagem na educação superior, a partir do entendimento dos envolvidos diretamente em tal processo, a saber: professores e alunos. Trabalhou-se também com teóricos que tratam especificamente da educação superior.

\section{Considerações Finais}

Ao longo do texto foram debatidas questões envolvendo o processo de ensino-aprendizagem na educação superior a partir do ponto de vista do professor e do aluno e seguindo uma perspectiva psicanalítica para fundamentar tais reflexões. Foi trazida à tona a maneira como funcionava a interação professor-aluno nos primórdios da educação superior no Brasil e como esta relação estava pautada na própria etimologia destas palavras: professor enquanto aquele que discursa/professa algo publicamente

16 Pulsão: refere-se à força energética que está subjacente à atividade do aparelho motor e funcionamento do psiquismo humano (ROUDINESCO; PLON, 1998). 
e aluno enquanto aquele que é alimentado, nutrido por algo que alguém (o professor) oferta. Esta ideia, de certa forma, entrou em desuso, na medida em que o aluno não é mais percebido enquanto um recipiente que deve ser preenchido de conteúdo/conhecimento e o professor não é visto, no atual contexto, como detentor de uma verdade absoluta que não possa ser posta em debate.

Não obstante, percebeu-se que ainda hoje o professor exerce um papel importante no processo de aquisição de conhecimento feito pelo aluno. Logo, este não pode prescindir daquele, pois, o docente promove um direcionamento sobre aquilo que o discente precisa conhecer, mas ao mesmo tempo estimula o desejo de saber, de ultrapassar as barreiras do dado imediato, da mesma forma que um filho, em determinada fase da vida, se espelha no pai e/ou mãe, se utilizando das referências que eles o proporcionaram da infância até a vida adulta no caminho de conquista da própria singularidade, da própria vida.

Entretanto, o professor precisa estar ciente das fantasias a que os alunos o vestem em seus psiquismos. Não pode responder a demanda de amor ou de ódio que muitas vezes os alunos o endereçam. Deve permanecer em terreno neutro, cuidando de analisar como afeta os discentes com o tipo de discurso que manifesta em sala de aula e como é afetado pelas manifestações transferências e identificatórias dos mesmos. Até na educação superior, o professor precisa assumir uma postura ética frente a sua conduta e compreender que estabelece com os discentes uma relação de desigualdade hierárquica - por mais que pense e diga o contrário, a fim de que não se envolva para além daquilo que precisa fazer em sua função de favorecer e estimular o desejo de saber dos estudantes.

\section{Referências}

ALMEIDA, S. F. C. O lugar da afetividade e do desejo na relação ensinar-aprender. In. Temas em Psicologia. N.1, 1993. Disponível em: <http://pepsic.bvsalud.org/pdf/tp/v1n1/v1n1a06.pdf >. Acesso em: 10 dez 14.

ASSIM MESMO. Disponível em: < In. http://letratura.blogspot.com.br/2006/04/etimologia-esemntica-professor.html> . Acesso em: 13 fev. 2015.

BAPTISTA, C. R. Inclusão em diálogo: algumas questões que insistem... In. Ensaios pedagógicos: III seminário nacional de formação de gestores e educadores - educação inclusiva: direito à diversidade. Brasília: Ministério da Educação. Secretaria de Educação Especial, 2006.

BACHA, M. S. C. N. O mestre e seus Feitiços. In. Freud pensa a educação. Revista Educação Especial: biblioteca do professor, n.1. São Paulo: Editora Segmento, 2006.

BUENO, S. Minidicionário da língua portuguesa. 2a ed. São Paulo: FTD, 2007.

BATTAGLIA, L. Laço social e relação com o saber. In. CESAROTTO, O. A. O discurso lacaniano. Revista Viver Mente e Cérebro, São Paulo, v. 4, 2005. 
DALGAlARRONDO, P. A afetividade e suas alterações. In. Psicopatologia e semiologia dos transtornos mentais. $2^{\mathrm{a}}$ ed. Porto Alegre: Artmed, 2008.

FILOSOFANDO. Disponível em: < In. http://frankvcarvalho.blogspot.com.br/2011/11/o-significadoda-palavra-aluno.html>. Acesso em 13 fev. 2015.

FORBES, J. Os eixos da subversão analítica: os quatro discursos. Conferência dada no Instituto da Psicanálise Lacaniana $\quad$ IPLA. $\quad$ S/d. $\quad$ Disponível em: $<$ http://www.psicanaliselacaniana.com/estudos/documents/Oseixosdasubversaoanaliticaosquatrodiscursos.pdf>. Acesso em: 13 fev. 2015.

FREIRE, P. A concepção bancária da educação como instrumento da opressão. Seus pressupostos, sua crítica. In. Pedagogia do Oprimido. 17ª ed. Rio de Janeiro: Paz e Terra, 1987.

Primeiras Palavras. In. Pedagogia da Autonomia: saberes necessários à prática educativa. Publicação Original: 1996. Digitalização: 2002. Disponível em: < www.sabotagem.revolt.org >. Acesso em: $04 \mathrm{dez} 14$.

FREUD. S. Algumas reflexões sobre a psicologia do escolar (1914). In. Totem e tabu e outros trabalhos (1913-1914). Edição standard brasileira das obras psicológicas completas de Sigmund Freud. Rio de Janeiro: Imago, 1996.

. Os caminhos da formação dos sintomas. In. Conferências introdutórias sobre psicanálise (1916-1917). Edição standard brasileira das obras psicológicas completas de Sigmund Freud. Rio de Janeiro: Imago, 1996.

Explicações, aplicações e orientações (1933). In. Novas Conferências introdutórias sobre psicanálise e outros trabalhos (1932-1936). Edição standard brasileira das obras psicológicas completas de Sigmund Freud. Rio de Janeiro: Imago, 1996.

. A dinâmica da transferência (1912). In. O caso Schreber, artigos sobre técnica e outros trabalhos (1911-1913). Edição standard brasileira das obras psicológicas completas de Sigmund Freud. Rio de Janeiro: Imago, 1996.

Observações sobre o amor transferencial (novas recomendações sobre a técnica da psicanálise III) (1915[1914]). In. O caso Schreber, artigos sobre técnica e outros trabalhos (1911-1913). Edição standard brasileira das obras psicológicas completas de Sigmund Freud. Rio de Janeiro: Imago, 1996.

GAETA, C. MASETTO, M. T. Como os alunos do ensino superior aprendem. In. O professor iniciante no ensino superior: aprender, atuar e inovar. Editora SENAC: São Paulo, 2013.

GIL, A. C. Métodos e técnicas de pesquisa social. São Paulo: Atlas, 1999.

LACAN, J. O Seminário, livro 10: A angústia (1962-1963). Texto estabelecido por Jacques-Alain Miller. Edição brasileira. Rio de Janeiro: Jorge Zahar Ed., 2005.

LAJONQUIÈRE, L. De Piaget a Freud: para repensar as aprendizagens (A [psico] pedagogia entre o conhecimento e o saber). $7^{\text {a }}$ ed. Editora Vozes: Petrópolis, 1998.

MASETTO, M. T. Professor universitário: um profissional da educação na atividade docente. In. Masetto, M. T. (Org.). Docência na universidade. Campinas: Papirus, 1998. 
MELLO, B. N. As teorias da linguagem em Lacan. Pontifícia Universidade católica do Rio de Janeiro, 2010 (Tese de doutorado).

ROLDÃO, M. C. Função docente: natureza e construção do conhecimento profissional. In. Revista Brasileira de Educação. v. 12 n. 34 jan./abr. 2007. Disponível em <http://www.scielo.br/pdf/rbedu/v12n34/a08v1234.pdf>. Acesso em 07 dez 14.

ROUDINESCO, E. PLON, M. Dicionário de Psicanálise. Rio de Janeiro: Zahar, 1998.

SILVESTRE, D. A questão do silêncio. In. Clínica lacaniana: casos clínicos do campo freudiano. Rio de Janeiro: Jorge Zahar Ed., 1994.

\section{Como citar este artigo (Formato ABNT):}

SILVA, D.S.S.; COSTA, R.M.L. Da Educação Superior: Um estudo sobre a Relação Professor-Aluno, à partir da perspectiva Psicanalítica. Id on Line Revista de Psicologia, Julho de 2015, vol.9, n.27. p. 38-51. ISSN 1981-1189.

Recebido: 21/05/2015

Aceito: 26/05/2015 